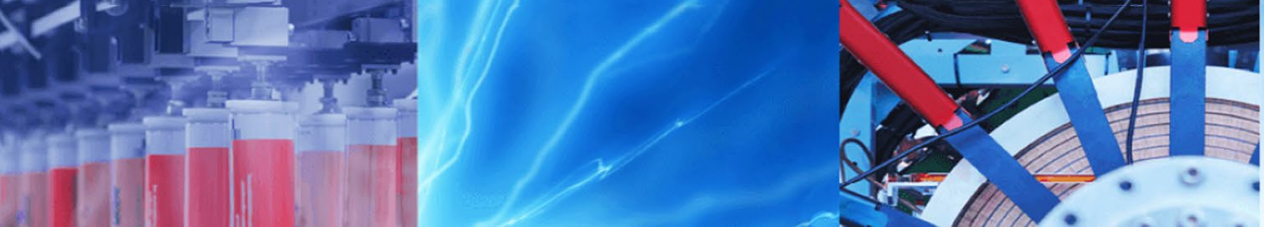

Research Article

\title{
Inconsistent variation of return periods of temperature extremum in China and its projection based on CMIP6 results
}

\author{
Xueyuan Kuang $^{1}$ D $\cdot$ Danqing Huang ${ }^{1} \cdot$ Ying Huang ${ }^{1}$
}

Received: 7 December 2020 / Accepted: 3 November 2021

Published online: 14 November 2021

(c) The Author(s) 2021 OPEN

\begin{abstract}
Increasingly extreme temperature events under global warming can have considerable impacts on sectors such as industrial activities, health, and transportation, suggesting that risk for these kinds of events under climate change and its regional sensitivity should be reassessed. In this study, the observation and multi-model simulations from CMIP6 are comprehensively used to explore the regional differences of the extreme temperature response to climate change from the perspective of return period (RP). The Gumbel model of generalized extremum distribution is applied to estimate the RP for the annual extremum of temperature based on Gaussian distribution of daily temperature. The analysis on the observation in selected three sites indicates that the regional inconsistency of RP variation is not only existed in extreme high temperature ( $\mathrm{HTx}$ ) but also in low temperature (LTn) during the past several decades. The annual amplitude of temperature extremum in the Northeast China is enlarged with summer becoming hotter and winter becoming colder while the opposite situation is detected in Huang-Huai River Basin with cooler summer and relatively stable winter, and South China is characterized by hotter summer and slight warmer winter. From the spatial distribution of the HTx and LTn variations of fix RP, it is found that the Northeast China and Jiang-Huai River Basin is the most sensitive areas, respectively, in the response of extreme low temperature and high temperature to global warming. However, the regional inconsistency of the extreme temperature change is only observed under SSP1-2.6 scenario in the CMIP6 simulation but gradually disappeared from SSP2-4.5 to SSP5-8.5.
\end{abstract}

Keywords Inconsistency $\cdot$ Return period $\cdot$ Extreme temperature $\cdot$ Projection · CMIP6

\section{Introduction}

Warm and cold extremes have been frequently occurred during recent several decades under global warming $[4$, $15,23,28,32,40]$. Numerous disasters caused by these extreme climate or weather events have been exerting profound influences on the economy, human lives and environmental sustainability, thereby arousing worldwide public awareness and scientific concern $[6,16,20$, $21,25,32]$. Intuitively, the warming climate could lead to a rise of extreme high temperature events and reduction of the opposite extremes. Both the winter extreme cold events and summer heatwave cases, however, have been increased in the recent two decades [15, 28, 40], implying that the amplitude of the annual extreme temperature is enlarged under the context of global warming. Furthermore, it is found that the asymmetry or inconsistency is not only observed in the seasonal variation of temperature but also existed in its spatial distribution [1, 23, 28], which means that the evolution of the extreme temperature events is very complicated under the comprehensive influences of multiple factors, and therefore, risk assessment based on these kinds of climate events should be reconsidered under climate change.

Xueyuan Kuang, xykuang@nju.edu.cn | 'School of Atmospheric Sciences, Nanjing University, Nanjing 210023, China. 
The return period (RP) or recurrence interval of extreme events refers to the average interval time that is greater than or equal to a certain threshold defined as the reciprocal of the occurrence frequency. Generally, the occurrence probability of extreme events is small but always initiate disasters, so the recurrence period is extensively applied as a design basis in engineering to estimate the potential risk of extreme events $[11,14,24]$. Meanwhile, understanding and predicting extreme events occurrence in the future is helpful for disaster prevention, mitigation measures and risk management. As the occurrence frequency of extreme events has been exhibiting an upward trend and causing increasing loss of economy in recent years, much attention has been paid to focus the potential risk reassessment of extreme events [18, 19, 31, 34]. Therefore, it is crucial to precisely quantify the recurrence interval of the extreme event, which is commonly calculated from the historical data but is comparable to or longer than the available record. Previous related work mostly focused the hydrological extreme events due to its severe impact on economy and human lives, and its RP is critically considered in water resources management [ 2 , $9,24,27,29,34]$. However, the natural disasters are generally a multivariate process instead of one single element event, which means that its occurrence probability should be comprehensively described by a multivariate analysis of various contributed variables [14, 24, 27]. Additionally, the stationary assumption of extreme events to estimate return period and risk may be problematic due to climate change $[7,8,13,26,29,33,38]$, so the temporally changing environment should be explicitly taken into consideration. For many industrial activities, estimation of extreme events in terms of a return level in a non-stationary context becomes necessary. Anthropogenic influence is estimated to prolong the occurrence interval of extreme low temperature events but substantially shorten the RP of extreme high temperature events $[17,42]$. Nevertheless, significant regional differences in the changes of extreme temperature events especially the cold events have been detected [4], implying that the reactions of the extreme temperature events in different regions to climate change cannot be considered as a whole. Taking the above into consideration, it is of significance and necessary to further explore the responses of the extreme temperature events and estimate its risk under climate change from the perspective of the recurrence period.

Since the Coupled Model Intercomparison Project in Phase 6 (CMIP6) results are available, the extreme temperature events are widely evaluated and projected based on the multi-model simulations but most work focus on the change of climate extreme indices by the ETCCDI $[3,12,22,36]$. In this study, we aim to draw a risk map of extreme temperature events under climate change by estimating and comparing annual extreme high and low temperature values based on return level. The rest of the paper is organized as follows. Section 2 describes the data and method. The RP change of the extreme temperature events based on observation is discussed in Sect. 3 and its projection under different scenarios from CMIP6 results is presented in Sect. 4. A summary and discussion are provided in Sect. 5.

\section{Data and method}

\subsection{Data}

Two datasets used in this paper are as follows:

1. The daily maximum ( $\mathrm{Tx})$ and minimum temperature $(\mathrm{Tn})$ in 724 meteorological sites of China with time spanning from 1951 to 2010 are from National Climate Center of China [39]. The 724 sites are spatially distributed in Fig. 1 with black dots. Three selected typical stations of Shuangliao, Kaifeng and Guangzhou, respectively, representing for the North, Center and South of Eastern China are marked with red.

2. The simulated daily maximum and minimum temperature from 2015 to 2100 under different scenarios of SSP1-2.6, SSP2-4.5, SSP3-7.0 and SSP5-8.5 are derived from CMIP6 results. Based on the performance of model in simulating the indices of extreme climate $[12,37,41], 10$ models, which show good adaptability to China climate, are selected and listed in Table 1.

\subsection{Method}

The RP is commonly calculated by the following formula with the annual maximum value of the specific variable:

$T=1 / P=1 /(1-F(x))$

where $T$ and $P$ are the RP and exceedance probability, respectively, and $F(x)$ is the cumulative distribution function for the annual extremum of the specific variable. In this study, the annual highest value of daily maximum temperature $(\mathrm{HTx})$ and the lowest value of daily minimum temperature (LTn) are considered for calculating the RP of the extreme temperature. Generally, the generalized extreme value (GEV) model is applied to estimate the probabilities of extreme events (e.g., $[12,35,36])$. The Gumbel model is one simplified form of the GEV that could be used to discuss the extremes of Gauss-distribution variables such as temperature $[5,10,30]$. As the original daily temperature is distributed as Gauss model, the annual extremum of temperature could be fitted with the Gumbel 
Fig. 1 Spatial distributions of 724 meteorological sites in China (Black dots) (Red marks are for three selected stations)

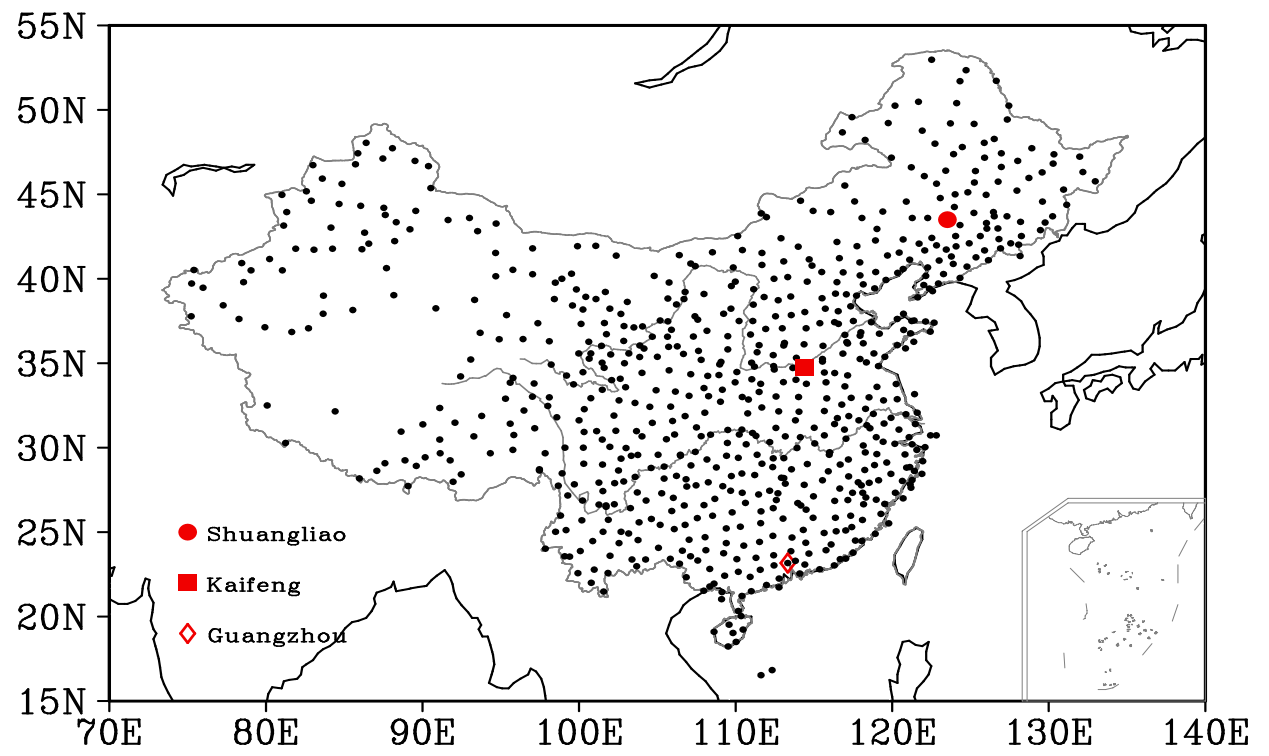

Table 1 The selected 10 models in CMIP6

\begin{tabular}{llc}
\hline Model & Developer & $\begin{array}{l}\text { Resolution (lon- } \\
\text { gitude } \times \text { latitude) }\end{array}$ \\
\hline ACCESS-ESM1-5 & Commonwealth Scientific and Industrial Research Organization, Australia & $192 \times 145$ \\
AWI-CM-1-1-MR & Alfred Wegener Institute, Germany & $384 \times 192$ \\
BCC-CSM2-MR & Beijing Climate Center, China & $320 \times 160$ \\
CanESM5 & Canadian Centre for Climate Modelling and Analysis, Canada & $128 \times 64$ \\
EC-Earth3 & EC-Earth-Consortium & $512 \times 256$ \\
INM-CM4-8 & Russian Academy of Science, Institute for Numerical Mathematics, Russia & $180 \times 120$ \\
IPSL-CM6A-LR & Institute Pierre Simon Laplace, France & $144 \times 143$ \\
MIROC6 & Japan Agency for Marine-Earth Science and Technology, Atmosphere and Ocean & $256 \times 128$ \\
& Research Institute, The University of Tokyo, Japan & $384 \times 192$ \\
MPI-ESM1-2-HR & Max Planck Institute for Meteorology, Germany & $320 \times 160$ \\
MRI-ESM2-0 & Meteorological Research Institute, Japan & \\
\hline
\end{tabular}

distribution, in which the probability $F(x)$ and probability density function $f(x)$ are listed as follows:

$$
\begin{aligned}
& F(x)=e^{-e^{-(x-b)}, \quad-\infty<x<+\infty} \\
& f(x)=\alpha e^{-\alpha(x-b)-e^{-\alpha(x-b)}}, \quad-\infty<x<+\infty
\end{aligned}
$$

where the $x$ is the random variable of HTx or LTn; $\alpha$ is the scale parameter and $b$ is the mode of distribution density; both are dependent on the sample distribution.

Meanwhile, as the resolutions of the selected 10 models are different, bilinear interpolation method is used in this study.

\section{Results from the observations}

\subsection{The examination of RP for the three typical stations}

The probability density function (PDF) is used to understand the distribution of the Tx and Tn. It should be noted that the raw data is first normalized based on each specific calendar day, and then normalized by all adjacent days. The PDF distributions of the Tx and Tn in the three selected stations accord with Gaussian distribution (Fig. 2), suggesting that the HTx and LTn samples 

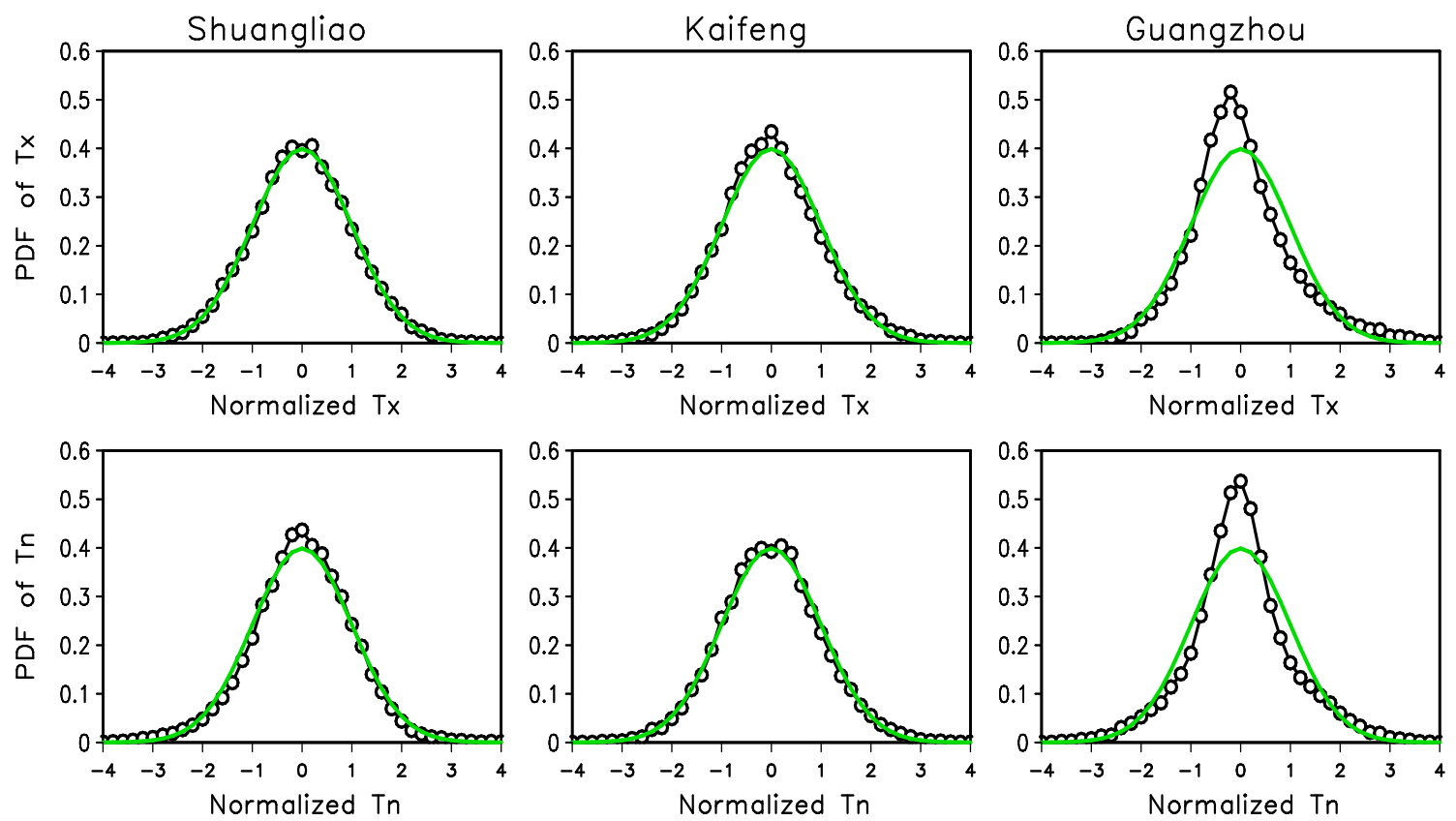

$$
\text { Q O Observation }
$$

Gauss distribution

Fig. 2 Probability density function (PDF) of the normalized daily maximum (Tx: Top panel) and minimum temperature (Tn: Bottom panel) for three selected stations, respectively

could be fitted with the Gumbel model of the generalized extremum distribution.

To examine the return level under climate change and assure the data sample is effective, two periods are selected: 1951-1990 (P1) and 1971-2010 (P2), which means the same period of 1971-1990 are mutually included in two samples. The fitting Gumbel distribution for three selected stations in two periods is presented in Fig. 3. Obviously, the distribution of HTx in Shuangliao shows slight difference in the two periods, indicating that the extreme high temperature remains stable during the last 60 years. However, the distribution in Kaifeng during the $\mathrm{P} 2$ shows a significantly leftward shift comparing to the P1. This suggests that the frequency of extreme high temperature in P2 is obviously lower than that in P1. Meanwhile, the distribution in Guangzhou is opposite to that in Kaifeng with the PDF peak in P2 is somewhat rightward shift in respect to $P 1$, implying the frequency of extreme high temperature in $\mathrm{P} 2$ stage is increased in contrast with $\mathrm{P} 1$. Thus, the regional difference in the distribution of $\mathrm{HTX}$ is significant in the two periods. Particularly, the HTx variation in central region of Eastern China exhibits its unique decline feature.

Different from the $H T x$, the distribution variation in LTn shows consistent among three stations with the PDF peak during $\mathrm{P} 2$ moving rightward in respect to $\mathrm{P} 1$ (Fig. 3). It means that the upward trend is dominant in the frequency variation of the extreme low temperature in all regions of Eastern China, which is in accordance with the global warming background.

Based on the fitting distribution of HTx and LTn with Gumbel model, the temperature extremum corresponding to the RPs from 5 to 200 years, respectively, derived from samples of two periods are analyzed as shown in Fig. 4. Compared to the P1, the higher HTx values are found during P2 in Shuangliao and Guangzhou. As the annual highest temperature absolutely occurs in summer season, the summer climate of the two stations in P2 is hotter than P1. The situation in Kaifeng is opposite with the green curve positioning below the black one, signifying that the HTx corresponding to specific RP derived from $\mathrm{P} 2$ is lower than that during $\mathrm{P} 1$ and the summer climate of this site is cooler than before. According to the LTn, the case in Shuangliao is significantly different from the other two stations. The LTn corresponding to specific RP in Shuangliao in P2 is obviously lower than that in $\mathrm{P} 1$ while little differences can be observed in the other two stations. Therefore, the regional inconsistency is not only detected in HTx change but also in LTn variation during the past several decades.

As above mentioned, the typical station in central and north region of the Eastern China exhibits the unique feature, respectively, in the extreme high and low temperature variation. Since the HTx (LTn) occurs in summer (winter), the annual amplitude of extreme temperature 

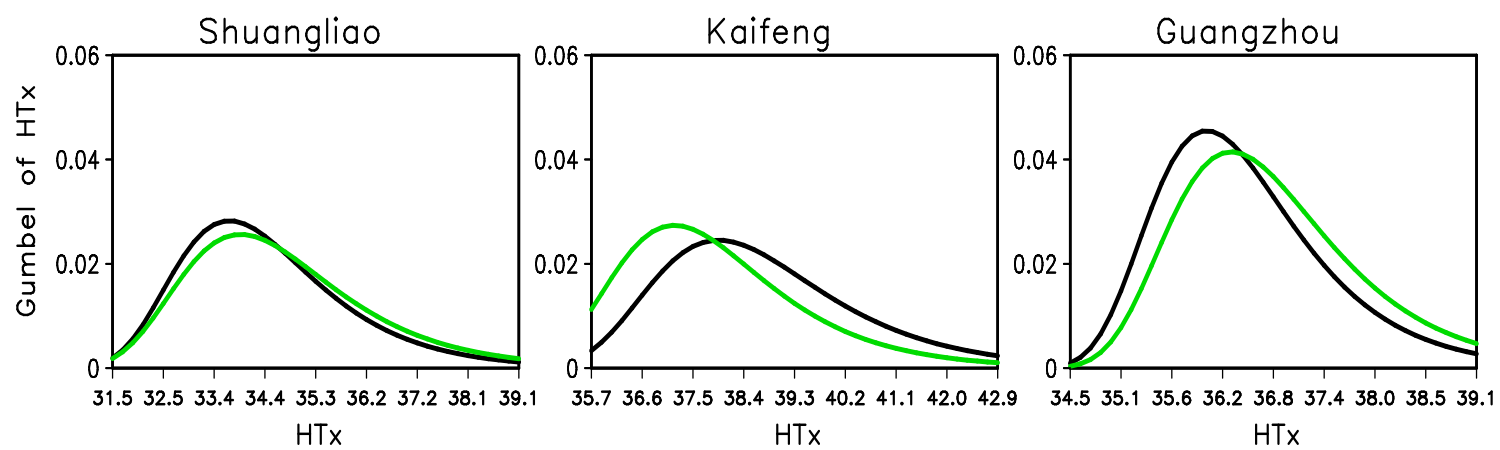

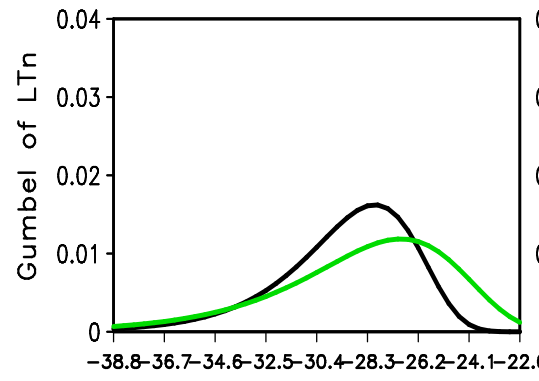

$\mathrm{LTn}$

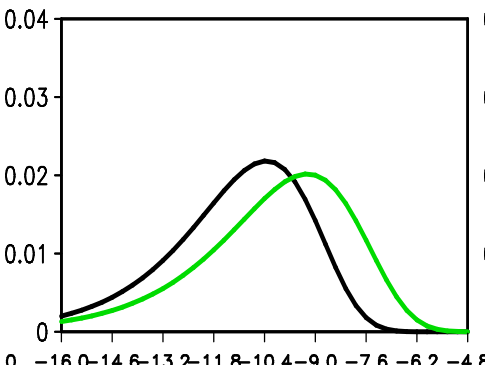

$\mathrm{LTn}$

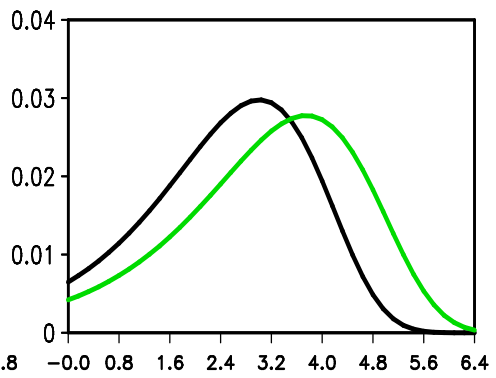

$\mathrm{LTn}$

$1951-1990$

$1971-2010$

Fig. 3 Gumbel distribution derived from observed HTx (Top panel) and LTn (Bottom panel) samples of three selected stations in two periods (The black line is for P1 and green for P2)
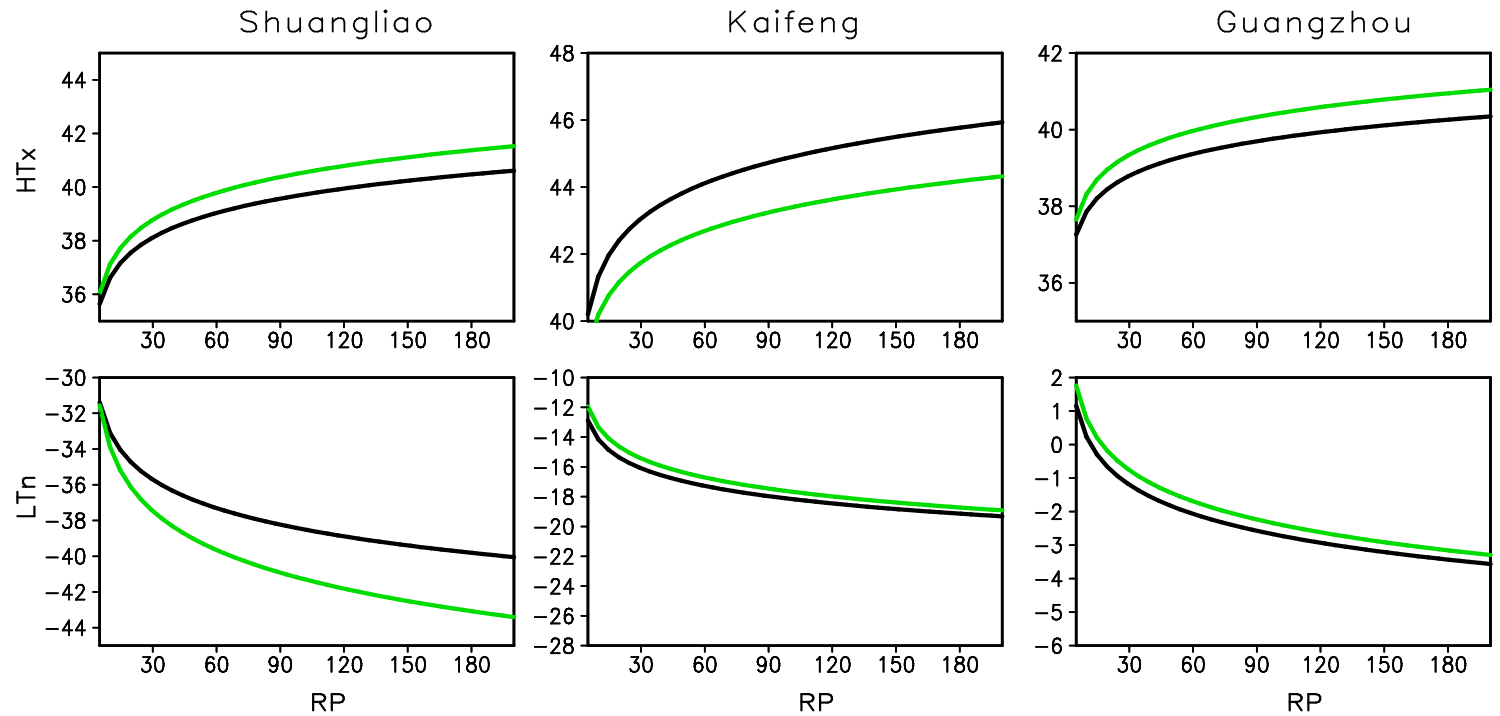

$1951-1990$

$1971-2010$

Fig. 4 Extreme values of different RP derived from observed HTx (Top panel) and LTn (Bottom panel) samples of three selected stations in two periods (The black line is for $\mathrm{P} 1$ and green for $\mathrm{P} 2$ )

is enlarged in the Northeast China. It suggests that hotter summer and colder winter frequently occurred over Northeast China in the past several decades. The opposite situation is detected in Huang-Huai River Basin with cooler summer and relatively stable winter, and the South China is characterized by hotter summer and slightly warmer winter. 

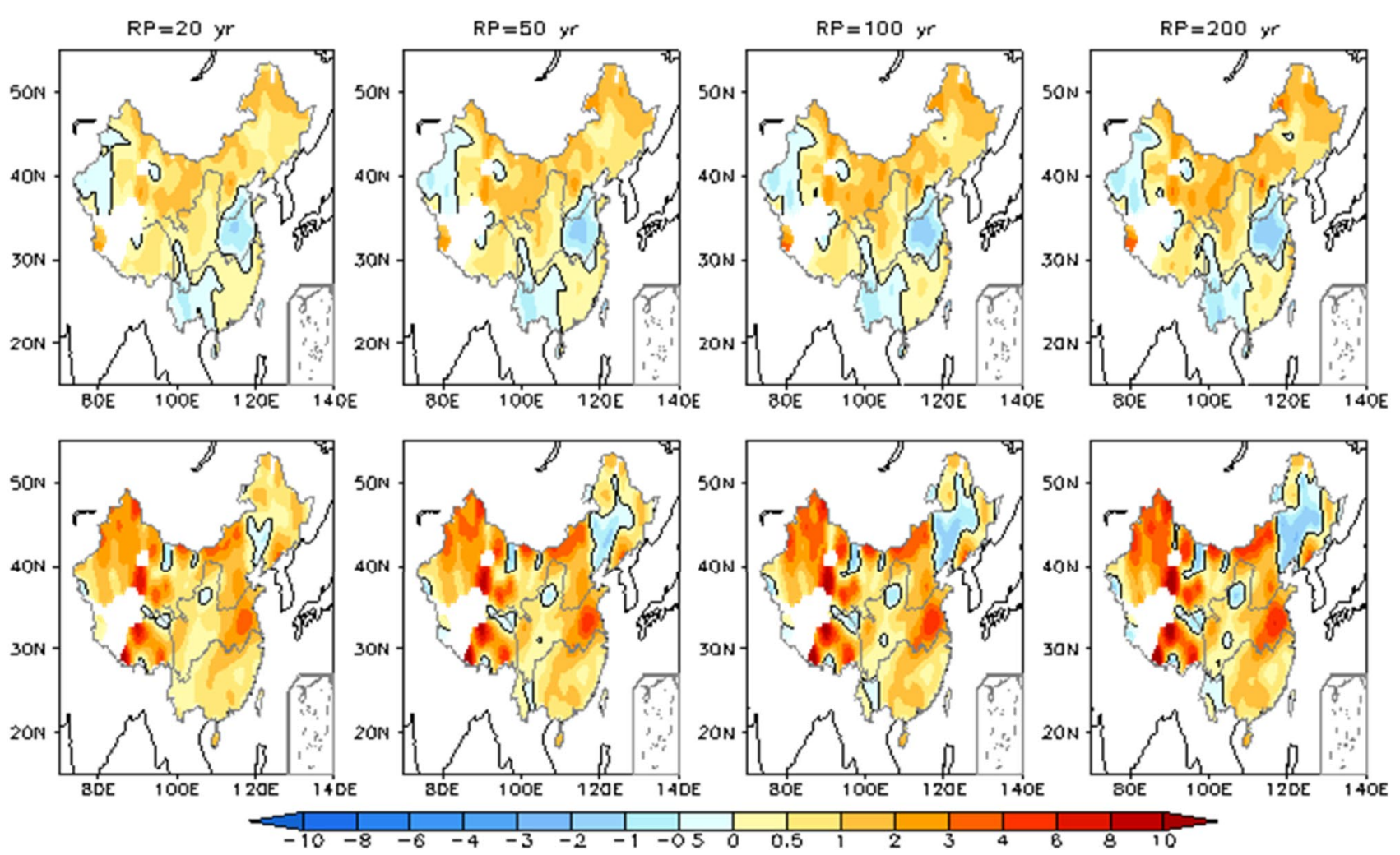

Fig. 5 Spatial difference distributions of HTx (Top panel) and LTn (Bottom Panel) between P2 and P1, respectively, corresponding to RP of $20,50,100$ and 200 years derived from observation

\subsection{The RP changes over China}

Figure 5 shows the spatial difference distributions of the HTX and LTn between two periods corresponding to the RP of 20,50,100 and 200 years, respectively. The increase (decrease) in the high temperature extremum of the specific RP from P1 to P2 means the summer becoming hotter (cooler) under climate change. Apparently, three regions with negative value are indicated in Fig. 5 as Huang-Huai River Basin, Southwest China and Western Xinjiang, where the extreme summer high temperature has dropped in the past several decades. Especially, the Huang-Huai River Basin, at where the Kaifeng site locates, exhibits the most significant change among the three regions. Except for that, the rest of China are consistently dominated by positive values. The magnitude has increased with the latitude, indicating a severe heating in Northern China in summer. For the LTn, it is mostly covered by positive values except for the part region of northeast China and several small regions east to the Plateau. The significant positive areas are located at the Huang-Huai River Basin and northwest China. As the rise (drop) of the low temperature extremum of the specific RP from P1 to P2 means the winter becoming warmer (colder) under climate change, the majority in China is characterized by the warming winter. The notable negative area is located at the northeast China, where extreme cold events frequently have occurred after 2000, also signifying the inconsistency of the low temperature extremum change in China under the global warming.

\section{Projection from CMIP6 simulation under different scenarios}

The similar analysis has been performed on the CMIP6 results under different scenarios. As the time of CMIP6 simulation spans from 2015 to 2100 , three sub-periods are divided: 2021-2060, 2041-2080, 2061-2100 marked as P3, P4 and P5, respectively. Figure 6 shows the multimodel ensemble mean of HTx changes with RP under different scenarios for the three typical stations. As the grids of models might not be accurately located at the three observed sites, we interpolate the values of neighboring grids into the observed sites after calculating the extreme temperature value of return level in the original model grids. Notice that under the SSP1-2.6 scenario, the HTx in Kaifeng gradually increases from P3 to P5 with larger distance between $\mathrm{P} 5$ and $\mathrm{P} 4$ but smaller gap between P4 and P3, while in Shuangliao and Guangzhou the difference of HTx between P5 and P4 can be 

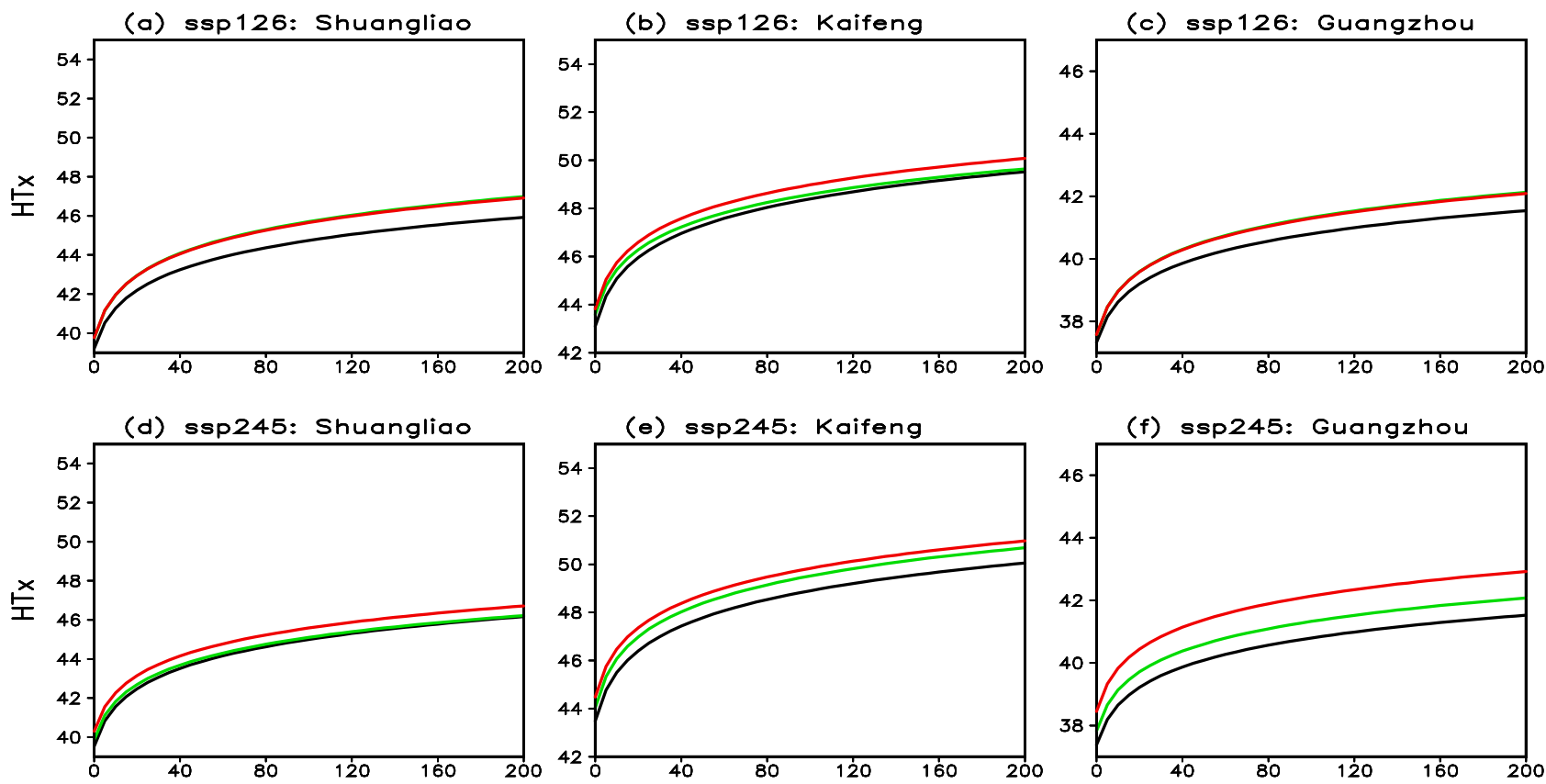

(e) ssp 245: Kaifeng
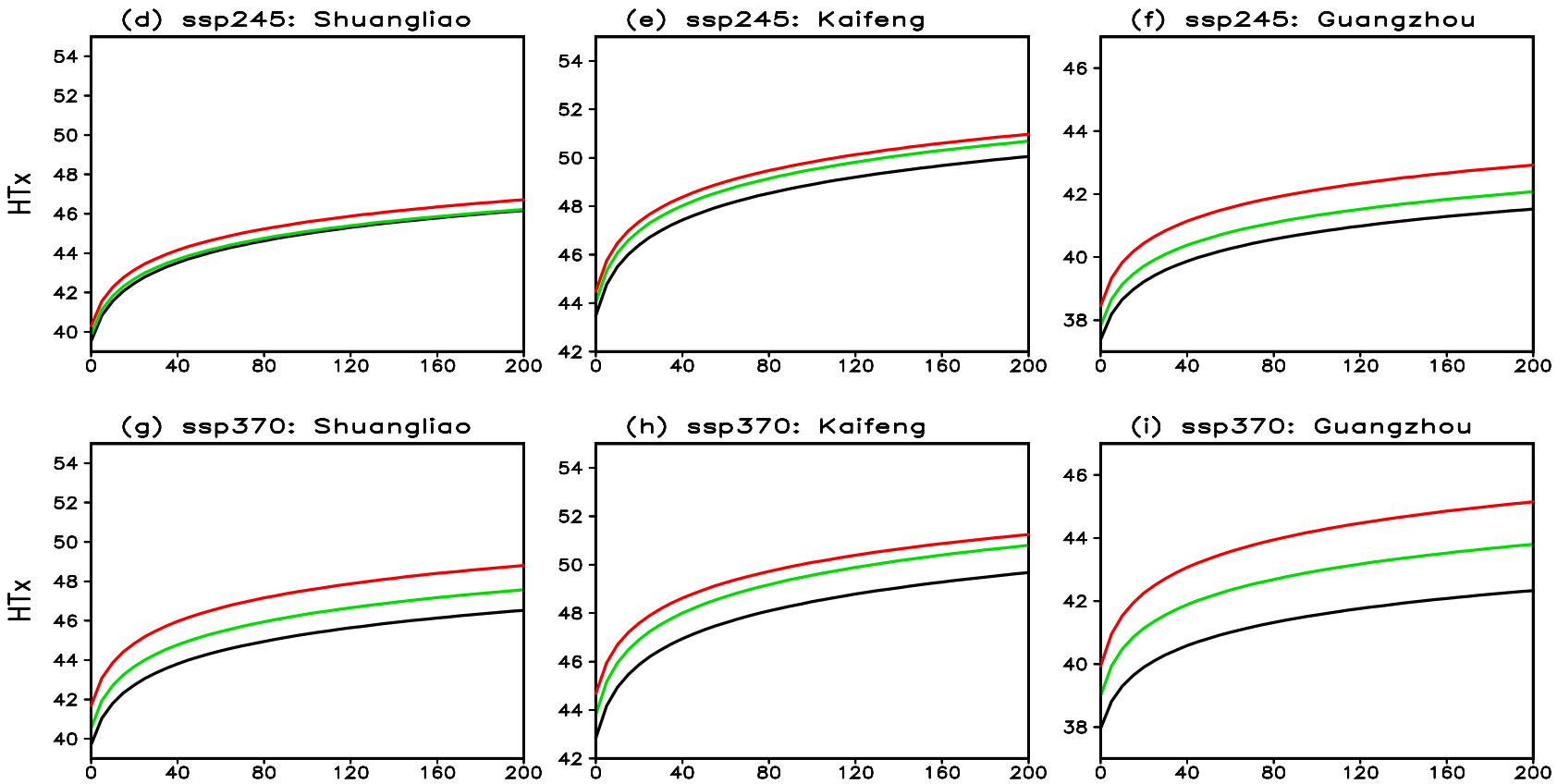

(h) ssp 370: Kaifeng
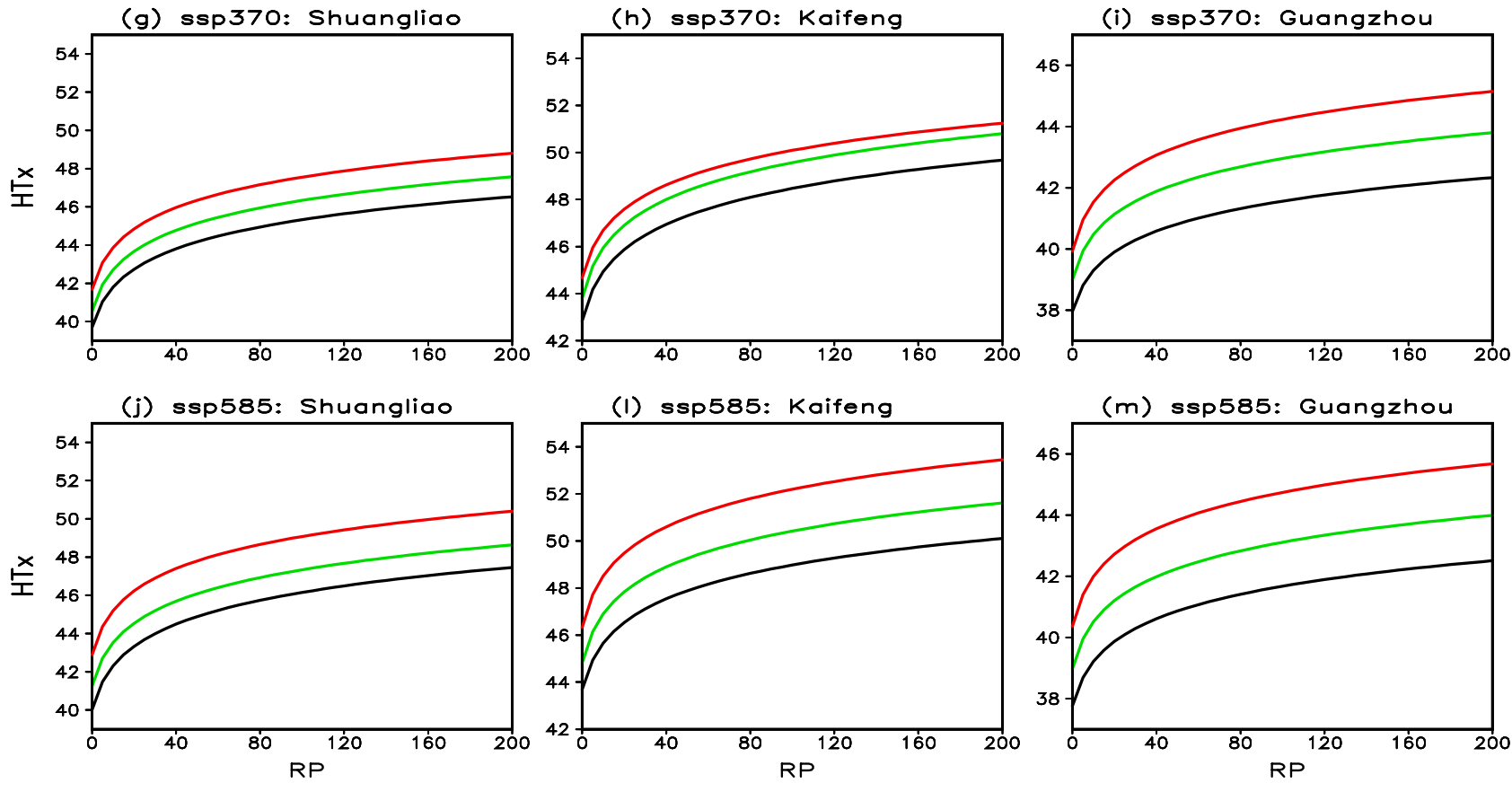

P3

P4

P5

Fig. 6 Ensemble mean of HTx changes with RP derived from simulated samples under different scenarios from SSP1-2.6 to SSP5-8.5 for three selected stations (The black line is for P3, green for P4 and red for P5)

negligible but significant between $\mathrm{P} 4$ and $\mathrm{P} 3$. The inconsistency also be observed in the HTx change under the scenario of SSP2-4.5. The rise of HTx in Shuangliao from P3 to P4 is far lower than that in the other two stations. Nevertheless, the HTx of three sites under SSP3-7.0 and SSP 5-8.5 are characterized by consistently increasing from $\mathrm{P} 3$ to $\mathrm{P} 5$.
The spatial difference distribution of HTx corresponding to RP of 50 years between two periods under different scenario is demonstrated in Fig. 7. As aforementioned, it should be noted that as the resolutions of the selected 10 models are different and interpolation of extreme values may cause data distortion, we calculate temperature extremum of return level and its difference between two 
Fig. 7 Spatial difference distribution of HTx with RP-50 yr between two periods under different emission scenarios (Units in ${ }^{\circ} \mathrm{C}$, the black dots are for the same symbol of models larger than 70\%)
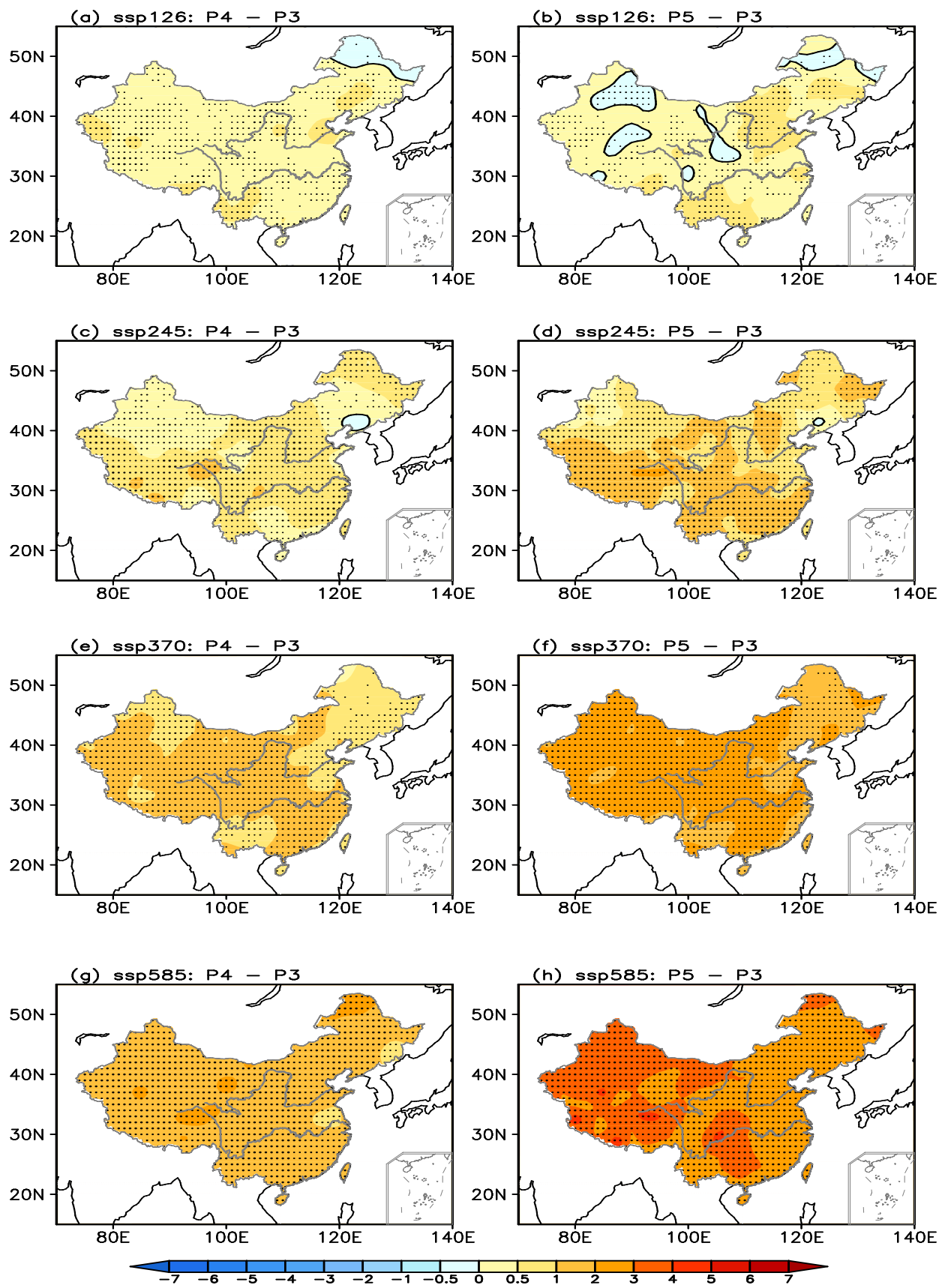

periods based on original data for each grid individually and then bilinearly interpolate the results into the same standard grid of $1^{\circ}$ (Longitude) $\times 1^{\circ}$ (latitude) for obtaining ensemble mean. From Fig. 7a under SSP1-2.6, the positive difference between $\mathrm{P} 4$ and $\mathrm{P} 3$ with magnitude below $0.5^{\circ} \mathrm{C}$ dominates the majority of China except for the northern region of Heilongjiang province, signifying that the summer in the mid-period of the next century will be hotter than the present. But the upward trend will not last to the late period as shown in Fig. 7b. More negative difference areas between $\mathrm{P} 5$ and $\mathrm{P} 3$ can be observed. Taking the same symbol ratio of models into consideration, the uncertainty and inconsistency of the $\mathrm{HTx}$ change under this scenario are significant. However, under the other three scenarios from SSP2-4.5 to SSP5-8.5 (Fig. 7c-h), the positive difference areas cover all over the China and the magnitude increase with time and emission intensity, indicating that the inconsistency and uncertainty of HTx change are significantly declined from SSP1-2.6 to SSP5-8.5. 


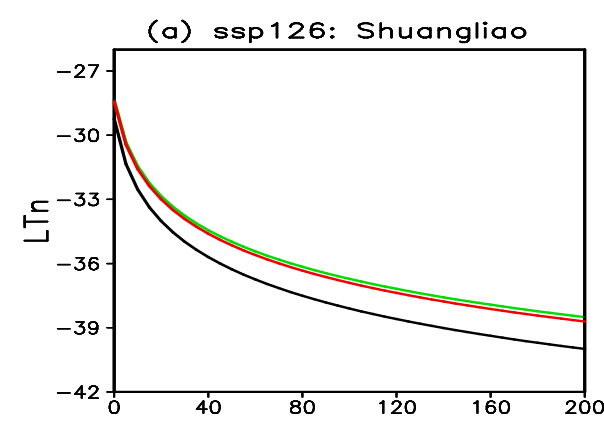

(b) ssp 126: Kaifeng

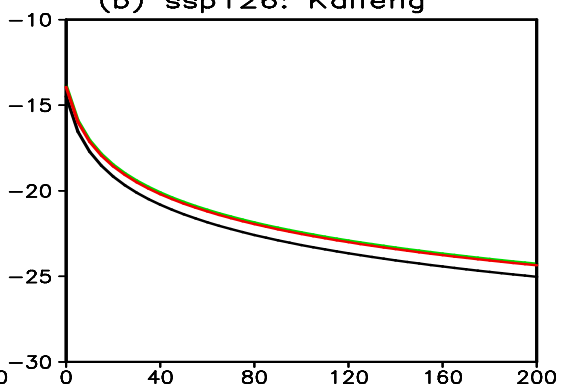

(e) ssp 245: Kaifeng
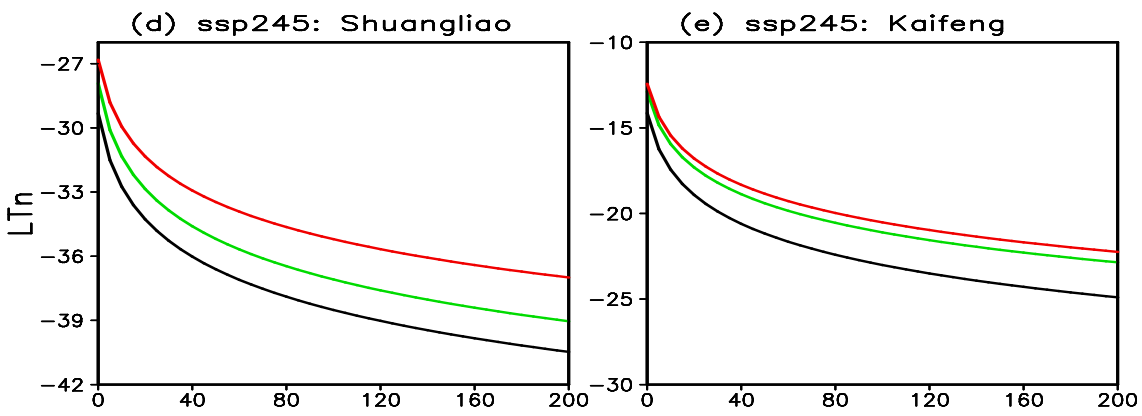

(h) ssp 370: Kaifeng
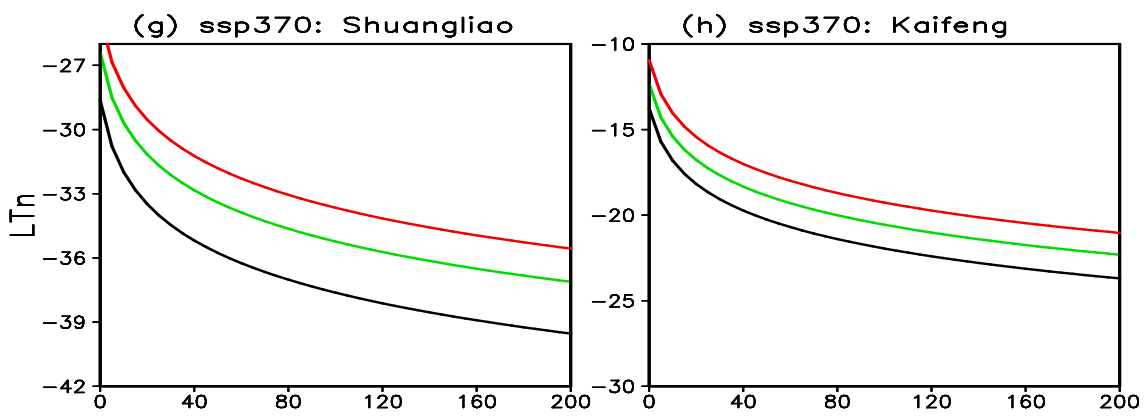

(1) ssp 585: Kaifeng

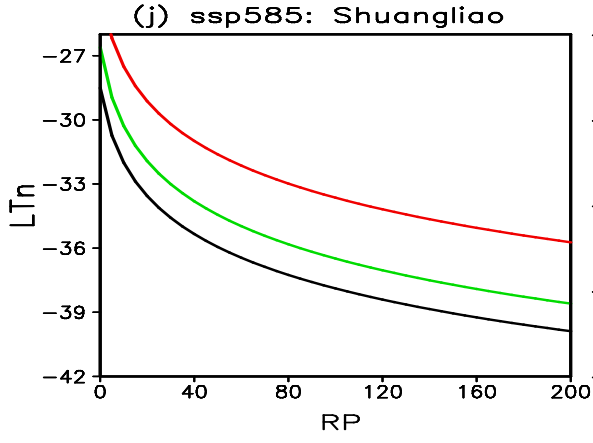

-10
-15
-20
-25
-30
$P 3$ (c) ssp 126: Guangzhou

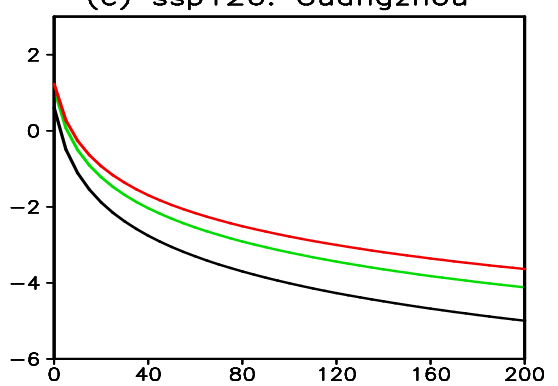

(f) ssp 245: Guangzhou

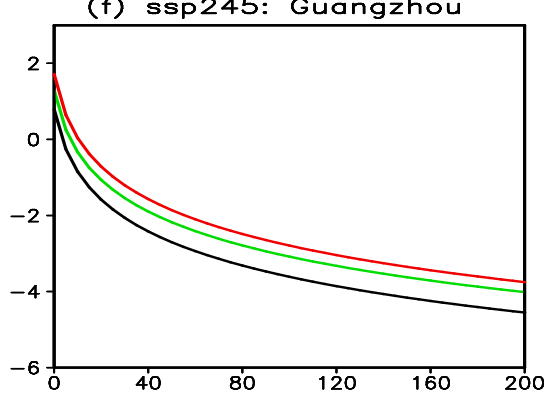

(i) ssp 370: Guangzhou

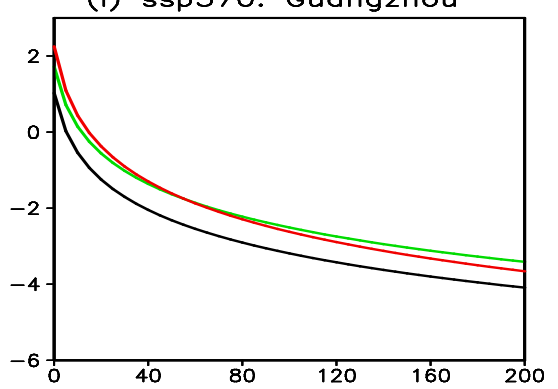

(m) ssp 585: Guangzhou

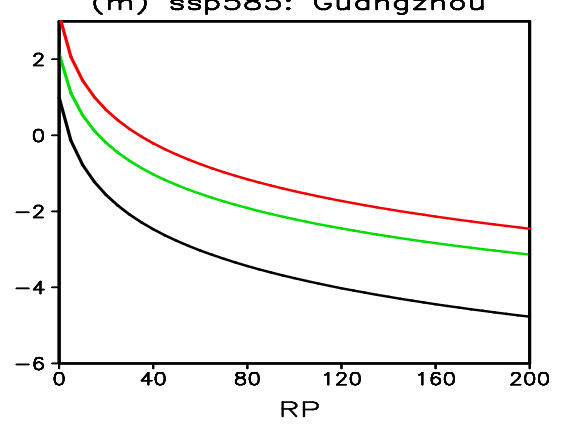

P5

Fig. 8 Same as Fig. 6 but for LTn

As to the LTn as demonstrated in Figs. 8 and 9, the similar variation as the HTx in Figs. 6 and 7 is observed, namely, the inconsistency is only found under the SSP1-2.6 scenario while it is disappeared from SSP2-4.5 to SSP5-8.5. Meanwhile, the LTn change in eastern China is more sensitive than that in western China. 
Fig. 9 Same as Fig. 7 but for LTn
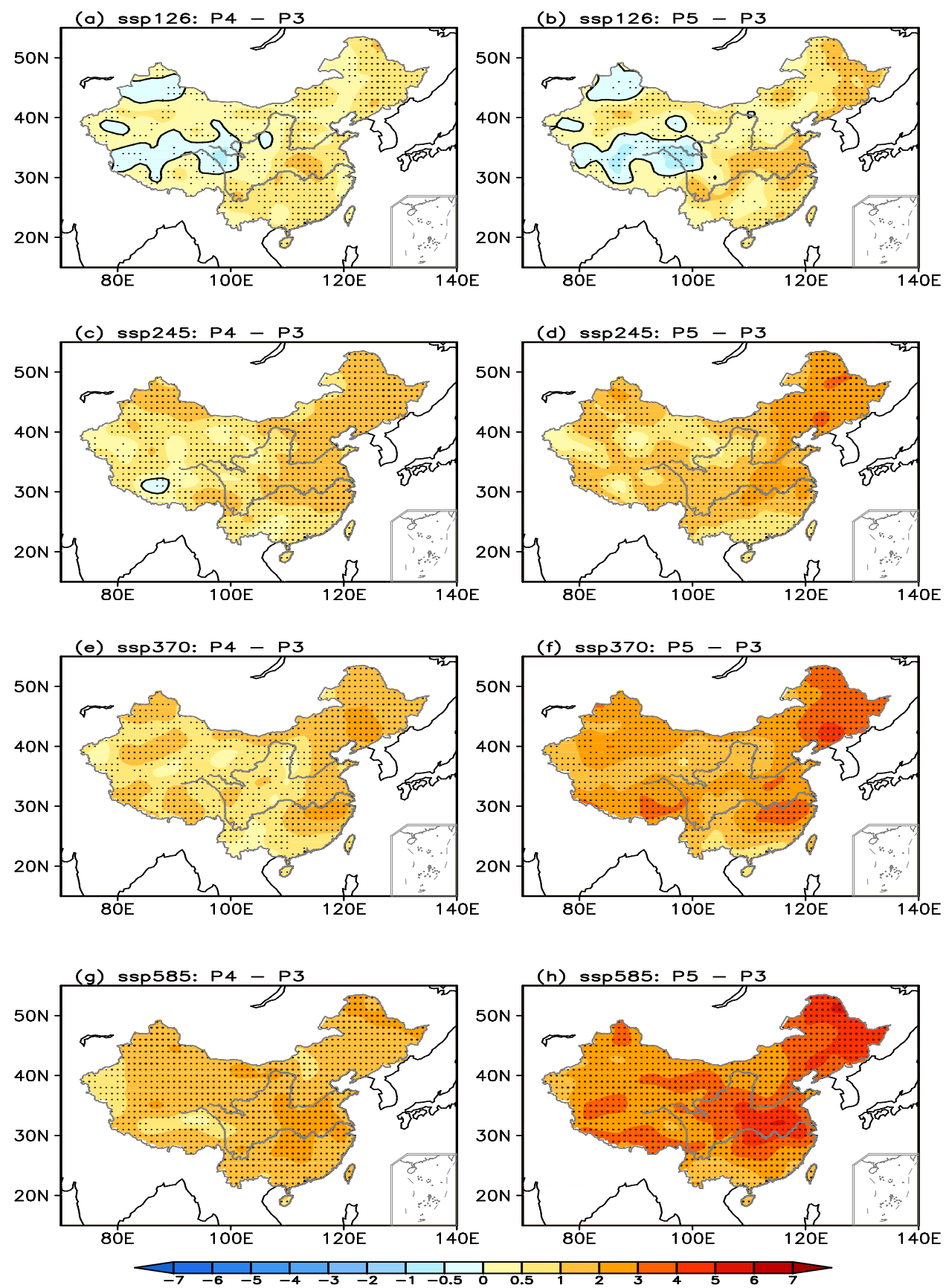

\section{Conclusion and discussion}

In this study, the observation in the past several decades and simulation from CMIP6 under different scenarios are used to comprehensively explore the changes of the extreme temperature under climate change from the angle of RP and risk assessment. The Gumbel model of generalized extremum distribution is introduced to estimate the RP for the annual extremum of temperature. The analysis on the observed data in three selected sites indicates that the regional inconsistency of RP variation is not only detected in HTx but also in LTn during the past several decades. The annual amplitude of extreme temperature in Northeast China is enlarged with summer becoming hotter and winter becoming colder while the different situation is detected in Huang-Huai River Basin with cooler summer and relatively stable winter, and South China is characterized by hotter summer and slight warmer winter. From the spatial distribution of the HTx and LTn variations of fix RP, it is found that the Northeast China and Jianghui River Basin is the most sensitive areas, respectively, in the response of extreme low temperature and high 
temperature to global warming. However, the inconsistency of the extreme temperature change is only observed in the CMIP6 simulation under SSP1-2.6 scenario but disappeared from SSP2-4.5 to SSP5-8.5. Above analysis indicate that risk of extreme temperature events is increased under the global warming but the regional inconsistency should be considered to some extent.

The risk change of extreme temperature events under climate change is estimated only based on temperature in this study. As aforementioned, the natural disaster is a multivariate process which is comprehensively affected by different elements. For example, the summer heatwave is always accompanied with the drought while the extreme cold events in winter occurs involving in snowfall or frozen rain process. The risk estimate or assessment for the extreme temperature events should be taken more elements into consideration instead of one variable. Moreover, the non-stationary series need to be considered due to the warming background. Additionally, the response of the RP of extreme temperature to climate change is anlyzed but its mechanism not discussed in this study which need to be further explored.

Funding This work is jointly supported by the National Key R\&D Program of China under Grant Nos. 2017YFA0603803 and 2016YFA0600504, and the National Natural Science Foundation of China under Grants Nos. 41775073, 41930969 and 42075020.

\section{Declarations}

Conflict of interest The authors declare no conflict of interest.

Open Access This article is licensed under a Creative Commons Attribution 4.0 International License, which permits use, sharing, adaptation, distribution and reproduction in any medium or format, as long as you give appropriate credit to the original author(s) and the source, provide a link to the Creative Commons licence, and indicate if changes were made. The images or other third party material in this article are included in the article's Creative Commons licence, unless indicated otherwise in a credit line to the material. If material is not included in the article's Creative Commons licence and your intended use is not permitted by statutory regulation or exceeds the permitted use, you will need to obtain permission directly from the copyright holder. To view a copy of this licence, visit http://creativecommons. org/licenses/by/4.0/.

\section{References}

1. Bell JL, Sloan LC, Snyder MA (2004) Regional changes in extreme climatic events. J Clim 17:81-87

2. Bonaccorso B, Cancelliere A, Rossi G (2003) An analytical formulation of return period of drought severity. Stoch Environ Res Risk Assess 17:157-174
3. Catalano AJ, Loikith PC, Neelin JD (2020) Evaluating CMIP6 model fidelity at simulating non-gaussian temperature distribution tails. Environ Res Lett 15(7):074026

4. Cattiaux J, Vautard R, Cassou C, Yiou P, Delmotte VM, Codron F (2010) Winter 2010 in Europe: a cold extreme in a warming climate. Geophys Res Lett 37:L20704

5. Coles $S$ (2001) An introduction to statistical modelling of extreme values. Springer, Great Britain

6. Coumou D, Rahmstorf S (2012) A decade of weather extremes. Nat Clim Change (March) 2(7):491-496

7. Degaetano AT (2009) Time-dependent changes in extremeprecipitation return-period amounts in the continental united states. J Appl Meteorol Climatol 48:2086-2099

8. Du T, Xiong L, Xu CY, Gippel CJ, Guo S, Liu P (2015) Return period and risk analysis of nonstationary low-flow series under climate change. J Hydrol 527:234-250

9. Fernandez B, Salas JD (1999) Return period and risk of hydrologic events. II: applications. J Hydrol Eng 4:309-316

10. Gumbel EJ (1958) Statistics of extremes. Columbia University Press, New York, p 375

11. Hurford AP, Parker DJ, Priest SJ, Lumbroso DM (2012) Validating the return period of rainfall thresholds used for Extreme Rainfall Alerts by linking rainfall intensities with observed surface water flood events. J Flood Risk Manag 5:134-142

12. Kim YH, Min SK, Zhang X et al (2020) Evaluation of the CMIP6 multi-model ensemble for climate extreme indices. Weather Clim Extremes 29:100269

13. Laurent C, Parey S (2007) Estimation of 100-year-return-period temperatures in France in a non-stationary climate: Results from observations and IPCC scenarios. Glob Planet Change $57: 177-188$

14. Li N, Liu X, Xie W, Wu J, Zhang P (2013) The return period analysis of natural disasters with statistical modeling of bivariate joint probability distribution. Risk Anal 33(1):134-145

15. Luo M, Ning G, Xu F et al (2020) Observed heatwave changes in arid northwest china: physical mechanism and long-term trend. Atmos Res 242:105009

16. Min SK, Cai W, Whetton $P$ (2013) Influence of climate variability on seasonal extremes over Australia. J Geophys Res Atmos 118:1-12

17. Mitchell JFB, Lowe J, Wood RA, Vellinga M (2006) Extreme events due to human-induced climate change. Philos Trans R Soc 364:2117-2133

18. Morton ID, Bowers J, Mould G (1997) Estimating return period wave heights and wind speeds using a seasonal point process model. Coast Eng 31(1-4):305-326

19. Naess A (1998) Estimation of long return period design values for wind speeds. J Eng Mech 124(3):252-259

20. Osborn TJ (2011) Winter 2009/2010 temperatures and a record-breaking North Atlantic Oscillation index. Weather 66(1):16-19

21. Palmer TN, Raisanen J (2002) Quantifying the risk of extreme seasonal precipitation events in a changing climate. Nature 415:512-514

22. Raghavendra A, Dai A, Milrad SM et al (2019) Floridian heatwaves and extreme precipitation: future climate projections. Clim Dyn 52:495-508

23. Rahmstorf S, Coumou D (2011) Increase of extreme events in a warming world. Proc Natl Acad Sci USA 108(44):17905-17909

24. Requena Al, Mediero L, Garrote L (2013) A bivariate return period based on copulas for hydrologic dam design: accounting for reservoir routing in risk estimation. Hydrol Earth Syst Sci 17:3023-3038

25. Rowe CM, Derry LE (2012) Trends in record-breaking temperatures for the conterminous United States. Geophys Res Lett 39:L16703 
26. Salas JD, Obeysekera J (2014) Revisiting the concepts of return period and risk for nonstationary hydrologic extreme events. J Hydrol Eng 19(3):554-568

27. Shiau JT (2003) Return period of bivariate distributed extreme hydrological events. Stoch Environ Res Risk Assess 17:42-57

28. Simolo C, Brunetti M, Maugeri M, Nanni T (2011) Evolution of extreme temperatures in a warming climate. Geophys Res Lett 38:L16701

29. Sivapalan M, Samuel JM (2009) Transcending limitations of stationarity and the return period: process-based approach to flood estimation and risk assessment. Hydrol Process 23:1671-1675

30. Steurer PM (1989) Methods used to create an estimate of the IOO-year return period of the air-freezing index. Frost-protected shallow foundation development program-Phase Ilfinal report, appendix A. Prepared for the society of the Plastics Industry, NAHB Res. Ctr., Upper Marlboro, Md

31. Sukhija BS, Rao MN, Reddy DV, Nagabhushanam P, Hussain S, Chadha RK, Gupta HK (1999) Timing and return period of major palaeoseismic events in the Shillong Plateau, India. Tectonophysics 308(1-2):53-65

32. Teng $\mathrm{H}$, Branstator $\mathrm{G}$, Wang $\mathrm{H}$, Meehl GA, Washington WM (2013) Probability of us heat waves affected by a subseasonal planetary wave pattern. Nat Geosci 6:1056-1061

33. Tsimplis MN, Marcos M, Pérez B, Challenor P, Garcia-Fernandez MJ, Raicich F (2009) On the effect of the sampling frequency of sea level measurements on return period estimate of extremesSouthern European examples. Cont Shelf Res 29:2214-2221

34. Volpi E, Fiori A (2014) Hydraulic structures subject to bivariate hydrological loads: return period, design, and risk assessment. Water Resour Res 50:885-897
35. Wang J, Han Y, Stein ML et al (2016) Evaluation of dynamically downscaled extreme temperature using a spatially-aggregated generalized extreme value (GEV) model. Clim Dyn 47:2833-2849

36. Wehner M, Stone D, Mitchell D et al (2018) Changes in extremely hot days under stabilized 1.5 and $2.0^{\circ} \mathrm{C}$ global warming scenarios as simulated by the HAPPI multi-model ensemble. Earth Syst Dyn 9:299-311

37. Webner MF (2020) Characterization of long period return values of extreme daily temperature and precipitation in the CMIP6 models: part 2, projections of future change. Weather Clim Extremes 30:100284

38. Wigley TML (2009) The effect of changing climate on the frequency of absolute extreme events. Clim Change 97:67-76

39. Wu J, Gao X (2013) A gridded daily observation dataset over China region and comparison with the other datasets. Chin J Geophys 56(4):1102-1111 (in Chinese)

40. Xu P, Wang L, Huang $P$ et al (2021) Disentangling dynamical and thermodynamical contributions to the record-breaking heatwave over central Europe in June 2019. Atmos Res 252:105446

41. Yao Y, Luo Y, Huang J-B (2012) Evaluation and projection of temperature extremes over China based on CMIP5 model. Adv Clim Change Res 3(4):179-185

42. Zwiers FW, Zhang X, Feng Y (2011) Anthropogenic influence on long return period daily temperature extremes at regional scales. J Clim 24:881-892

Publisher's Note Springer Nature remains neutral with regard to jurisdictional claims in published maps and institutional affiliations. 